\title{
Modulation of responses to stress by estradiol benzoate and selective estrogen receptor agonists
}

\author{
Lidia I Serova, Heather A Harris ${ }^{1}$, Shreekrishna Maharjan and Esther L Sabban \\ Department of Biochemistry and Molecular Biology, New York Medical College, Valhalla, New York 10595, USA \\ ${ }^{1}$ Women's Health and Musculoskeletal Biology, Wyeth Research, Collegeville, Pennsylvania 19426, USA \\ (Correspondence should be addressed to E L Sabban; Email: sabban@nymc.edu)
}

\begin{abstract}
Previously, pretreatment with estradiol benzoate (EB) was found to modulate the response of hypothalamic-pituitary-adrenal (HPA) axis and gene expression in several catecholaminergic neuronal locations in ovariectomized (OVX) rats exposed to single immobilization stress (IMO). Here, we investigated the role of estrogen receptor (ER) subtypes, using selective agonists for ER $\alpha$ (propyl pyrazole triol, PPT) or ER $\beta$ (WAY-200070) in two major central noradrenergic systems and the HPA axis after exposure to single and repeated IMO. OVX female rats received 21 daily injections of either EB $(25 \mu \mathrm{g} / \mathrm{kg})$, PPT $(10 \mathrm{mg} / \mathrm{kg})$, WAY-200070 (10 mg/kg), or vehicle. Injections of EB and PPT, but not WAY-200070, elicited reduced body weight and increased uterine weight, showing their selectivity. Both EB and PPT increased corticosterone levels about two- to threefold, but prevented any further rise with either single or repeated

IMO, indicating an ER $\alpha$ (ESR1)-, but not ER $\beta$ (ESR2)-, mediated mechanism. In the locus coeruleus (LC), the rise in dopamine- $\beta$-hydroxylase $(D b h)$ mRNA with both stress paradigms was abrogated in EB- or PPT-injected animals. However, WAY-200070 blocked the response of $D B H$ mRNA to single IMO but not to repeated IMO. In the nucleus of the solitary tract (NTS), the rise in tyrosine hydroxylase and $D B H$ mRNAs with both IMOs was absent, or greatly attenuated, in EB- or PPT-treated rats. In most cases, WAY-200070 inhibited the response to single IMO but not to repeated IMO. The results demonstrate that pretreatment with estradiol, or ER-selective agonists, modulates the stress-triggered induction of gene expression of norepinephrine biosynthetic enzymes in LC and NTS, with ER selectivity depending on duration of the stress. Journal of Endocrinology (2010) 205, 253-262
\end{abstract}

\section{Introduction}

It is now widely appreciated that there are distinct genderrelated differences in stress-responses and in susceptibility to stress-associated disorders (Baum \& Grunberg 1991, Figueiredo et al. 2002, Kajantie \& Phillips 2006). Women are more susceptible than men to stress-related neuropsychiatric diseases. It is crucially important to determine the cause for this differential susceptibility. Gonadal steroids, such as estradiol, are proposed to play an important role in influencing these gender-related differences (Walf \& Frye 2005, Scharfman \& MacLusky 2008, Stovall \& Pinkentorn 2008). Estrogens have been found to modulate the functions of several physiological systems and their responses to stress in humans and animals. The stress-induced elevation of hormones of hypothalamic-pituitary-adrenal (HPA) system, ACTH and corticosterone, is higher in females than in males (Critchlow et al. 1963, Burgess \& Handa 1992, Patchev et al. 1995, Dayas et al. 2000, Young et al. 2001, Serova et al. 2005). Ovariectomy (OVX) of adult rats reduces plasma ACTH and corticosterone levels, an effect reversed by estradiol replacement (Burgess \& Handa 1992). Treatment of OVX rats with estrogen also reduces the induction of c-Fos in the paraventricular nucleus (PVN) of the hypothalamus in response to footshock (Ter Horst et al. 2009). In women, cortisol levels are significantly decreased after menopause, and can be restored with estrogen replacement therapy (Helgason et al. 1981). Long-term estradiol supplementations lead to faster restoration of increased blood pressure during stress and tend to reduce the immobilization-induced cardiac dysfunction in OVX rats (Serova et al. 2005, Ueyama et al. 2007). Estrogens also modulate functions of catecholaminergic (CA) systems under basal conditions and in response to stress, affecting gene expression for catecholamine biosynthetic enzymes in central and peripheral noradrenergic systems (Liaw et al. 1992, Arbogast \& Hyde 2000, Pau et al. 2000, Serova et al. 2005). We have previously shown that in OVX female rats, estradiol benzoate (EB) can differentially modulate response of HPA axis and catecholamine biosynthetic enzyme genes to single immobilization (IMO) stress in several CA regions, including the brain noradrenergic nuclei of locus coeruleus (LC) and the nucleus of the solitary tract (NTS) as well as in adrenal medulla (Serova et al. 2005). Several of the responses were attenuated, while some were 
actually opposite those of control animals. The IMO stress-triggered elevation in plasma ACTH levels was lessened in EB-pretreated animals. Similarly, with stress in EB-treated animals, there was no further change or even decline for mRNA levels of tyrosine hydroxylase $(T h)$, the initial and generally rate-limiting enzyme of CA biosynthesis, in adrenal medulla and the NTS, and dopamine- $\beta$-hydroxylase $(D b h)$ mRNA levels in the LC.

However, the responses to estrogens are tissue specific, and may depend on the specific estrogen receptor (ER) subtype expressed. The biological actions of estrogens are mediated by two different, but related, ER subtypes, ER $\alpha$ (ESR1) and ER $\beta$ (ESR2), belonging to the nuclear hormone receptor superfamily (reviewed in McKenna et al. (1999a) and Klinge (2001)). Estrogens activate multiple intracellular signaling pathways depending on the receptor subtype and on its subcellular localization, which can be in the membrane or nucleus (Enmark \& Gustafsson 1999, McKenna et al. 1999b, Patrone et al. 2000). The characterization of mice lacking $\operatorname{ER} \alpha, \operatorname{ER} \beta$ or both ERs revealed that they have overlapping and also unique roles in estrogen-dependent functions in vivo (reviewed in Pfaff et al. (2002), Matthews \& Gustafsson (2003) and Harris (2007)). ER $\beta$ is suggested to be crucially involved in regulating non-reproductive behaviors and brain development. Female ER $\beta$ knockout (KO) mice display increased anxiety and reduced cognitive function (Krezel et al. 2001). The distribution of the ER subtypes is such that many of the CA-specific regions express both $\mathrm{ER} \alpha$ and $\mathrm{ER} \beta$, although the ratio varies with location and gender (Laflamme et al. 1998, Shughrue \& Merchenthaler 2001).

Studies in cell culture revealed that transcriptional regulation of the Th gene by estrogens differed depending on ER subtype. In PC12 cells, $17 \beta$-estradiol triggered an elevation of Th transcription with ER $\alpha$ and a reduction with ER $\beta$ (Maharjan et al. 2005). In contrast to the Th gene, estradiol upregulates $\mathrm{D} b h$ gene expression and promoter activity with both ER subtypes (Serova et al. 2002, Sabban et al. 2010).

It remains to be determined in vivo whether selective activation of ER-specific subtypes also has differential effects on CA biosynthetic enzyme gene expression. Therefore, ER-selective agonists were administered in this study. We determined both basal effects and response to stress. The studies so far were restricted to examining the effects of single exposure to IMO, while many of the harmful effects of stress are associated with prolonged or repeated exposure (reviewed in Sabban \& Kvetnansky (2001), Sabban (2007) and Kvetnansky et al. (2009)). Here, we examine whether some of the variation in the ability of EB to modulate the response to stress depends on the selective ER subtypes, which are activated in the specific CA location. To address this issue, we have administered EB or ER subtype-selective agonists and determined their effect on the response to single stress as well as to repeated stress.

\section{Materials and Methods}

\section{Animals}

All experiments described were performed in accordance with the National Institute of Health Guide and Use of Laboratory Animals (NIH Publications no. 80-23), and were approved by the New York Medical College Animal Care and Use Committee.

Adult OVX Sprague-Dawley female rats (230-250 g) were obtained from Taconic Farms (Germantown, NY, USA) 8 days after the surgery. Purina Lab chow (\#53001) and water were available ad libitum, and the rats were maintained four per cage under controlled conditions on a $12 \mathrm{~h}$ light: $12 \mathrm{~h}$ darkness cycle at $23 \pm 2{ }^{\circ} \mathrm{C}$. Six days later, they were randomly divided into four subgroups ( 24 rats each), and treated with either $25 \mu \mathrm{g} / \mathrm{kg}$ of EB (Sigma), $10 \mathrm{mg} / \mathrm{kg}$ of ER $\alpha$ agonist propyl pyrazole triol (PPT; Stauffer et al. 2000), $10 \mathrm{mg} / \mathrm{kg}$ of ER $\beta$ agonist WAY-200070 (Malamas et al. 2004), or vehicle (10\% DMSO/90\% sesame oil, Sigma) once daily for 21 days by $50-\mu$ s.c. injections into the nape of the neck. PPT and WAY-200070 were synthesized by Wyeth Research, Collegeville, PA, USA.

This dose of EB has been shown in our previous studies to effectively modulate the response of noradrenergic neurons to single IMO stress (Serova et al. 2004, 2005) and increased plasma estradiol levels to $800 \pm 61 \mathrm{pg} / \mathrm{ml} 3 \mathrm{~h}$ after the injection (Serova et al. 2004). These doses of PPT and WAY-200070 are based on previously published studies with mature rats (Harris et al. 2002, Miller et al. 2005). For example, a dose of $10 \mathrm{mg} / \mathrm{kg}$ PPT daily injected to rats for 21 days elicited lordosis-induced negative feedback inhibition of LH release and prevented weight gain by OVX. It also provided protection against ischemia-induced cell death in hippocampal neurons (Miller et al. 2005). The dose of $15 \mathrm{mg} / \mathrm{kg}$ significantly reduced hot flushes in OVX females (Harris et al. 2002). A similar dose of WAY-200070 or DPN was found to significantly decrease anxiety-related behavior (Lund et al. 2005, Weiser et al. 2009).

All animals were weighed on the 15th day. On the 16th day, all treatment groups were subdivided into three subgroups of eight animals each, and they continued to receive the daily drug injections as before. One subgroup was subjected to repeated daily IMO stress for $2 \mathrm{~h}$ each for six consecutive days (days 16-21). A second subgroup received a single 2-h IMO, $1 \mathrm{~h}$ after the injection on day 21 . These animals were killed by decapitation on the 21st day immediately after the IMO. The third subgroup was not immobilized and was killed on the same day as the other animals from the same treatment and served as a control for the stress.

After decapitation, blood was collected into EDTAcontaining prechilled tubes. Uteri were isolated and weighed. The brain was removed, and the LC, as well as the rostral-medial and caudal parts of the NTS, were immediately dissected using a tissue slicer with digital micrometer (Stoelting Co., Wood Dale, IL, USA). Frontal sections, $13 \cdot 2-14 \cdot 2$ and $14 \cdot 2-15 \mathrm{~mm}$, from bregma were 
taken for rostral-medial and caudal portions of the NTS respectively, and $9 \cdot 2-10 \cdot 4-\mathrm{mm}$ frontal sections were taken for the LC. The slices were placed in ice-cold saline, and the bilateral regions of the LC and NTS were punched out and immediately frozen in liquid nitrogen.

\section{Isolation of RNA and quantitative RT-PCR}

Total RNA was isolated and analyzed as previously described (Serova et al. 1999, 2005). Briefly, the tissue from each animal was homogenized in RNA-Stat-60 (Tel-Test, Inc., Friendswood, TX, USA) and purified with RNAqueous-Micro RNA Isolation Kit (Ambion, Austin, TX, USA; Serova et al. 2004, 2005). The amount of total RNA from each sample was quantified using Ribo-Green fluorescent dye (Molecular Probes, Eugene, OR, USA).

Quantitative analysis of $T h$ and Dbh mRNA levels was performed by real-time RT-PCR with SYBR Green I with LightCycler (Roche Molecular Biochemicals) as previously described (Serova et al. 2005). The RT reactions were performed separately with $T h$ - or $D b h$-specific primers $5^{\prime}$-TCAGGCTCCTCTGACAG-3' and $5^{\prime}$-AGGCTGCAAGGCTTCTGTGATGGC- $3^{\prime}$ respectively in $5-\mu 1$ PCR mixture $(1 \times$ AMV buffer, $10 \mathrm{mM}$ dNTP, 8 units RNAse inhibitor, 1.25 units AMV, $10 \mu \mathrm{M}$ reverse primer, and $1 \mu \mathrm{g}$ of template RNA). Twenty-microliter PCRs were set up with a final concentration of $1 \times$ LightCycler DNA Master SYBR Green I, $0.5 \mu \mathrm{M}$ of each of the forward and reverse primers, $5 \mathrm{mM} \mathrm{MgCl}$, and $2 \mu \mathrm{l}$ of the standard cDNA or cDNA with unknown concentration. Standard curves plotted using serial dilutions from $2 \mathrm{ng}$ to $0.2 \mathrm{pg}$ of a Th or Dbh cDNA were used for the quantification by Fit Points Method. The following primers were used: for $T h, 5^{\prime}$-TGAACCAATTCCCCATGTGG-3', $5^{\prime}$-TGAACCAGTACACCGTGGAGAG- ${ }^{\prime}$; for $D b h$, 5'-CCACGCCATGCAGTTCTTCACCA-3', 5'-AGGCTGCAAGGCTTCT-GTGATGGC- $3^{\prime}$. The expected sizes of target sequences were confirmed with melting curve analysis by comparing its melting temperature with the melting temperatures of the standards as a positive control. The values for $T h$ and $D b h$ mRNA were normalized to levels of total RNA.

\section{Determination of plasma corticosterone levels}

Corticosterone levels were determined by using the ${ }^{125}$ I corticosterone RIA Kit (ICN, Costa Mesa, CA, USA) according to the manufacturer's protocol. Plasma was diluted 1:200 and incubated with ${ }^{125}$ I-labeled corticosterone and antiserum to corticosterone at room temperature for $2 \mathrm{~h}$. After centrifugation, the ${ }^{125} \mathrm{I}$ in the precipitates was measured in gamma counter and compared with the standard curve for quantification. The intra- and inter-assay coefficients of variation for corticosterone assays were $17 \cdot 2$ and $11 \cdot 2 \%$ respectively.

\section{Statistical analysis}

The results were evaluated by one- and two-way ANOVA. For two-way ANOVA, we determined the significance of the main factors, treatment and stress, and their interaction, followed by Bonferroni's Multiple Comparison Test using GraphPad and InStat programs. A value of $P \leq 0 \cdot 05$ was considered significant.

\section{Results}

\section{Body and uterine weights}

The body and uterine weights in the different treatment groups are shown in Table 1. As expected long-term treatment of the OVX females with EB led to significantly reduced body weight compared with the vehicle-treated group of rats. The effects of selective agonists for ER $\alpha$ (PPT) and ER $\beta$ (WAY-200070) on body weight were different. Injections of PPT, similar to $\mathrm{EB}$, reduced body weight. In contrast, there was no change in body weight with WAY200070. The mean weight of the uterus was about tenfold greater in EB-treated animals than in the control vehicletreated animals. PPT treatment also led to the elevation of uterine weight, but to a lesser extent than with EB. The uterine weights of rats treated with WAY-200070 did not differ from those of the vehicle-treated group.

\section{Changes in corticosterone levels}

Plasma levels of corticosterone were significantly changed by the treatments $(F=9 \cdot 14, P<0 \cdot 0002)$. Administration of EB or PPT led to about $2 \cdot 5$-fold higher corticosterone levels compared to treatment with vehicle $(P<0 \cdot 01$ and $P<0.05$ respectively) or WAY-200070 $(P<0.01$ and $P<0.05$ respectively; Fig. 1A). The changes in response to stress for the different groups were analyzed by two-way ANOVA. There were significant effects of stress $\left(F_{84,2}=19 \cdot 6, P<0 \cdot 0001\right)$ and treatment $\left(F_{84,3}=10 \cdot 2 \quad P<0 \cdot 0001\right)$, as well as interaction $\left(F_{84,6}=2 \cdot 7, P<0 \cdot 02\right)$. Although the concentrations of plasma corticosterone in stressed rats in the various groups were similar, the magnitude of rise above the levels of their respective unstressed controls varied. The pattern of the

Table 1 Body and uterine weights in ovariectomized (OVX) female rats with different treatments

\section{Uterine weight $(\mathrm{g})$}

\section{Treatment}

Vehicle

EB

PPT

$$
\begin{gathered}
0 \cdot 08 \pm 0 \cdot 004 \\
0 \cdot 85 \pm 0 \cdot 191^{*} \\
0 \cdot 51 \pm 0 \cdot 054^{*}+ \\
0 \cdot 097 \pm 0 \cdot 009
\end{gathered}
$$

WAY-200070
Body weight (g)

$309 \cdot 5 \pm 3 \cdot 7$

$238 \cdot 3 \pm 2 \cdot 4^{*}$

$248 \cdot 1 \pm 3 \cdot 6^{*}$

$295 \pm 5 \cdot 0$
${ }^{*} P<0.001$ versus vehicle, ${ }^{+} P<0.01$ versus $\mathrm{EB}$. 

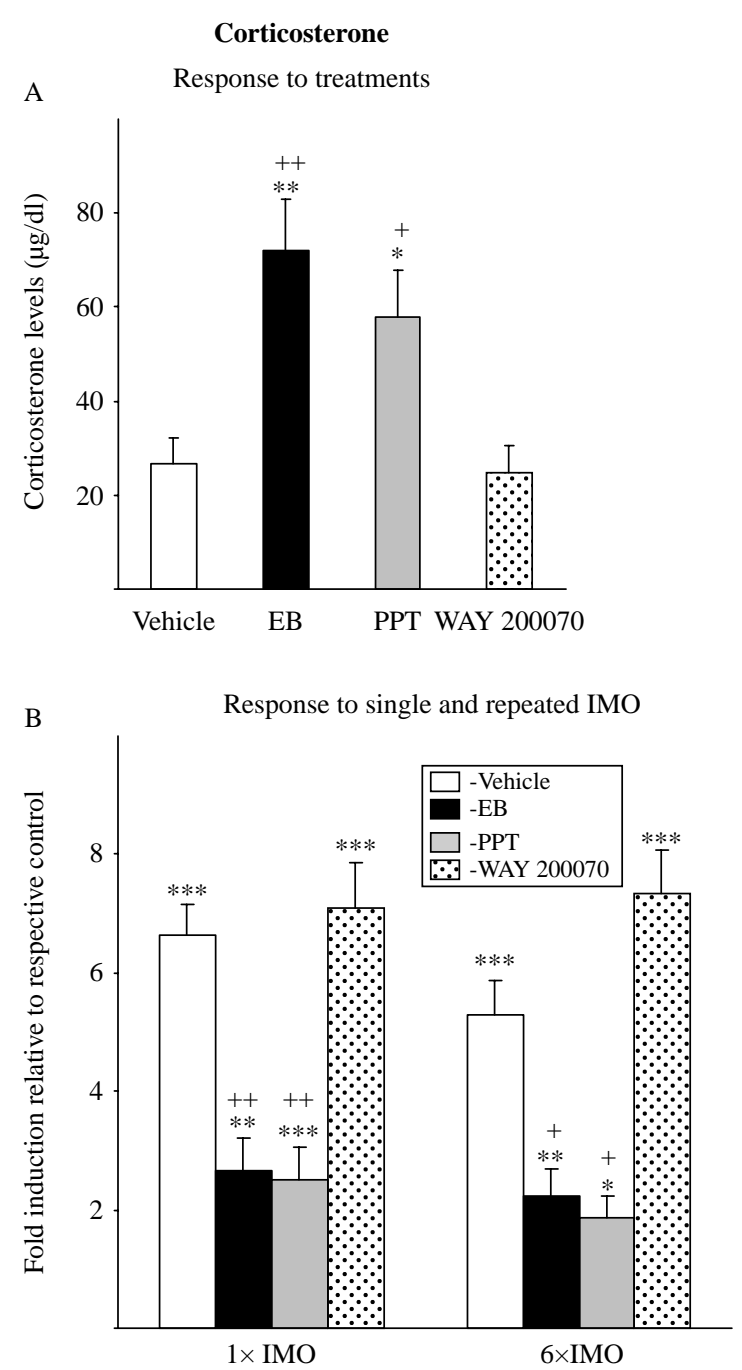

Figure 1 Effect of long-term administration of EB or ER subtype-selective agonists to OVX female rats on plasma corticosterone levels following single or repeated immobilization stress. (A) Plasma corticosterone levels after long-term injections of vehicle, EB, PPT, or WAY-200070. Data are expressed as mean \pm S.E.M. with $6-8$ samples per group. ${ }^{*} P<0 \cdot 05,{ }^{* *} P<0 \cdot 01$ versus vehicle, ${ }^{+} P<0 \cdot 05,{ }^{+}{ }^{+} P<0 \cdot 01$ versus WAY-200070 by Bonferroni's multiple comparison test. (B) Response to single $(1 \times)$ or repeated $(6 \times) \mathrm{IMO}$ stress. Data are expressed as mean \pm s.E.M. with the levels of corticosterone in the respective treatment taken as 1 . ${ }^{*} P<0 \cdot 05,{ }^{* *} P<0 \cdot 01,{ }^{* * *} P<0 \cdot 001$ versus respective unstressed controls; ${ }^{+} P<0 \cdot 05,{ }^{+}+P<0 \cdot 01$ vs $1 \times 1 \mathrm{IMO} /$ vehicle or $6 \times \mathrm{IMO} /$ vehicle by Bonferroni's multiple comparison test.

changes with single and repeated IMO was similar (Fig. 1B). With vehicle or WAY-200070, there was a significant, about sevenfold, elevation of plasma corticosterone levels after single $(1 \times)$ IMO. Similar results were obtained with repeated $(6 \times)$ IMO. Rats receiving injections of EB or PPT had much smaller increase of about twofold above the levels in unstressed animals with the same treatments. The responses of EB- and PPT-treated rats to single stress were significantly $(P \leq 0 \cdot 01)$ different from the response of the vehicle-treated animals. Similar results were obtained with exposure to $6 \times \operatorname{IMO}(P \leq 0 \cdot 05)$.

\section{Gene expression of catecholamine biosynthetic enzymes}

Locus coeruleus There was a significant effect of stress $\left(F_{84,2}=11 \cdot 1, \quad P<0 \cdot 0001\right)$ and treatment $\left(F_{84,3}=15 \cdot 3\right.$ $P<0 \cdot 0001)$, as well as interaction $\left(F_{84,6}=9 \cdot 9, P<0 \cdot 0001\right)$ on $D b h$ mRNA levels. Dbh mRNA levels in control animals which received the vehicle were elevated about fourfold with single IMO, and about twofold above the levels in unstressed rats with repeated IMO (Fig. 2). Injections with EB or either of the ER agonists effectively prevented the response of Dbh mRNA to single IMO. Moreover, treatment with EB and PPT abolished the response to repeated IMO as well. In rats treated with WAY-200070, repeated IMO still elicited a significant rise in Dbh mRNA, and did not differ significantly from the response of the vehicle-treated rats. As previously shown (Serova et al. 2005), we did not find changes in Th mRNA levels in the LC of OVX rats in response to stress (data not shown).

Nucleus of the solitary tract None of the drugs administrated significantly changed Th mRNA levels in the rostral-medial nor caudal NTS, except for a small, but significant, rise in Th mRNA in the caudal portion of the NTS in the PPT-treated group (Fig. 3A and C). In both rostral-medial and caudal regions, there were significant main effects of stress $\left(F_{84,2}=3.9, \quad P<0.02\right.$ and 14.8 , $P \leq 0 \cdot 0001)$ and treatment $\left(F_{84,3}=10 \cdot 6, \quad P<0 \cdot 0001\right.$ and 17.6, $P<0 \cdot 0001)$ respectively. The interaction was also significant $\left(F_{84,6}=3 \cdot 2, P<0 \cdot 01\right.$, and $\left.6 \cdot 3, P<0 \cdot 0001\right)$. The pattern of changes with single IMO in the different groups was similar in both parts of the NTS (Fig. 3B and D). Single IMO triggered about threefold elevation in Th mRNA levels in rostral-medial NTS and 2.5-fold rise in the caudal NTS of the vehicle-treated rats. In rats treated with PPT, WAY-200070, or EB, exposure to single IMO stress did not elevate Th mRNA. With repeated stress, only the EB- and PPT-treated groups differed from the vehicletreated controls.

Dbh mRNAs in the rostral-medial and caudal NTS were affected by the treatments $(F=3 \cdot 9, \quad P<0 \cdot 02$, and $3 \cdot 4$, $P<0.03$ respectively) with levels significantly elevated above vehicle, only in rats treated with PPT (Fig. 4A and C). In the rostral-medial NTS, no main effects or interaction was found by two-way ANOVA (Fig. 4B). In the caudal NTS, there were significant main effects of stress $\left(F_{84,2}=4 \cdot 2\right.$, $P<0 \cdot 02)$ and treatment $\left(F_{84,3}=7 \cdot 6, P<0 \cdot 0002\right)$, with a significant interaction $\left(F_{84,6}=2 \cdot 4, P<0 \cdot 03\right)$. In the caudal NTS, both single and repeated IMO stress elicited about twofold induction of Dbh mRNA levels in vehicle-treated rats, but not in any of the other groups (Fig. 4D). 


\section{Locus coeruleus}

Dbh mRNA
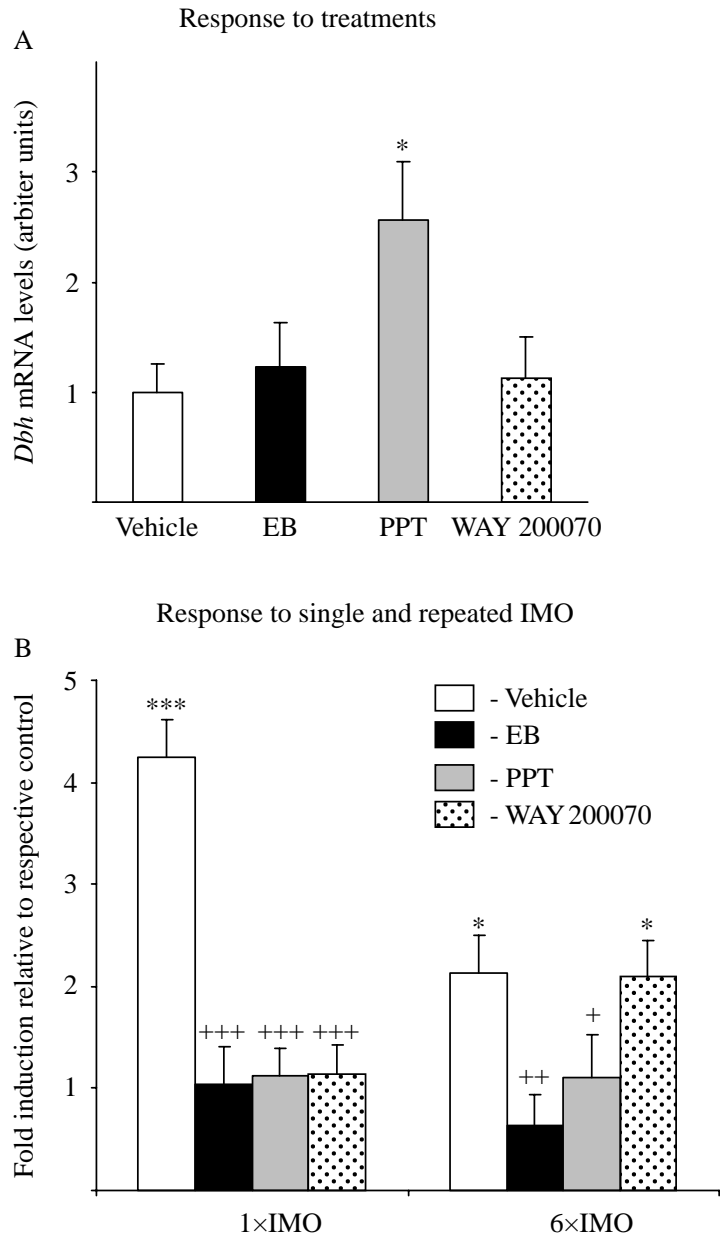

Figure 2 Effect of long-term administration of EB or ER subtype-selective agonists to OVX female rats on Dbh mRNA levels in the LC following single or repeated immobilization stress. (A) Relative Dbh mRNA levels expressed as mean \pm s.E.M. (6-8 samples per group) with levels in vehicle-treated rats taken as 1. ${ }^{*} P<0 \cdot 05$ versus vehicle. (B) Response to single $(1 \times)$ or repeated $(6 \times)$ IMO stress. Data are expressed as mean \pm S.E.M. with levels of $D b h$ mRNA with respective treatment in unstressed animals taken as $1 .{ }^{*} P<0 \cdot 05,{ }^{* * *} P<0.001$ versus respective unstressed controls; ${ }^{+} P<0.05,{ }^{++} P<0.01,{ }^{++}+P<0.001$ vs $1 \times 1 \mathrm{MO} /$ vehicle or $6 \times \mathrm{IMO} /$ vehicle by Bonferroni's multiple comparison test.

\section{Discussion}

This is the first study to our knowledge to investigate the ER selectivity on the regulation of gene expression of catecholamine biosynthetic enzymes in the brain noradrenergic neurons by estrogens and their role in modulation of the response to acute and chronic stress. Overall, the results indicate that the ER $\alpha$ is especially important in mediating the effects of estradiol on basal expression of Th and $D b h$ and on modulation of the response to both single and repeated stress in OVX female rats. However, ER $\beta$ is involved mostly in modulation of acute stress reactions. The findings indicate that these treatments can prevent excessive response of $\mathrm{TH}$ and $\mathrm{DBH}$ genes to stress.

The results of this study revealed, for the first time, that long-term activation of either $\operatorname{ER} \alpha$ or $\operatorname{ER} \beta$ changed the response of $D b h$ mRNA levels in the LC to acute stress. In rats injected with the ER $\alpha$ agonist PPT, the response to both durations of IMO stress was absent, and Dbh mRNA was unchanged beyond the higher basal level. Pretreatment with the ER $\beta$ agonist, WAY-200070, which in contrast to PPT, did not change basal unstressed levels, also abolished the response of Dbh mRNA to a single IMO. However, long-term stimulation of ER $\beta$ failed to reduce elevation of Dbh mRNA in the LC with repeated stress. This has important implications for stress-mediated behavior, and can influence vigilance and attention in potentially threatening environments. In male animals, various types of stress, including IMO, were shown to trigger marked elevations in $T h$ and Dbh gene expression in the LC (Smith et al. 1991, Melia et al. 1992, Rusnak et al. 1998, Wang et al. 1998, Serova et al. 1999, Osterhout et al. 2005), reviewed in Sabban \& Kvetnansky (2001) and Kvetnansky et al. (2009). In contrast, in the OVX female rats with low estradiol levels, IMO stress is not effective to trigger an elevation in the LC of Th mRNA, and only Dbh mRNA levels are increased.

The LC is sexually dimorphic with more $T h$ - and $D b h$ positive cells observed in female mice and rats (Luque et al. 1992, Pendergast et al. 2008). In female rats, both ER subtypes are found within the LC, with predominate expression of ER $\beta$ (Shughrue et al. 1997, Mitra et al. 2003). However, the findings reveal that ER $\beta$ is more involved with single IMO rather than with repeated IMO. The effect of an ER $\beta$ agonist on the response of the LC to stress is especially important since functions of these receptors are linked to affective disorders, and decreased levels of ER $\beta$ were found in persons committing suicide (Ostlund et al. 2003). The anti-depressant role of ER $\beta$ has been demonstrated in ER $\beta$ KO mice and with specific pharmacological manipulations (Walf \& Frye 2008, Walf et al. 2009). Significantly decreased anxiety-like and depressive-like behaviors were found in OVX females injected with WAY-200070 (Weiser et al. 2009). Potential changes in ER subtypes expressed in the LC induced by selective agonists and stress or in combination remain to be determined. We can speculate that a chronic strong stress, such as IMO, may decrease the expression of ER $\beta$ and raise the incidence of stress-related depression.

This study is also the first showing that in noradrenergic neurons of the NTS, gene expression of Th significantly increases in response to repeated stress, as previously seen for single IMO (Serova et al. 2005). Dbh gene expression was elevated by IMO stress with both durations in caudal NTS but in the rostral-medial NTS only with repeated IMO. The NTS is involved in the assimilation and integration of multiple viscerosensory processes, including cardiovascular control mechanisms, and also in osmoregulatory functions 

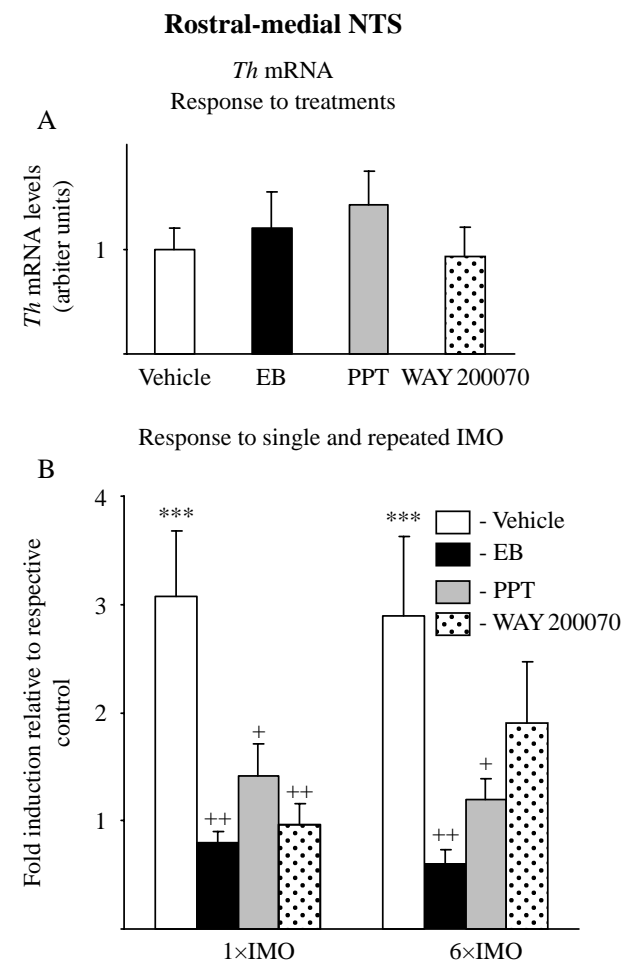

Caudal NTS
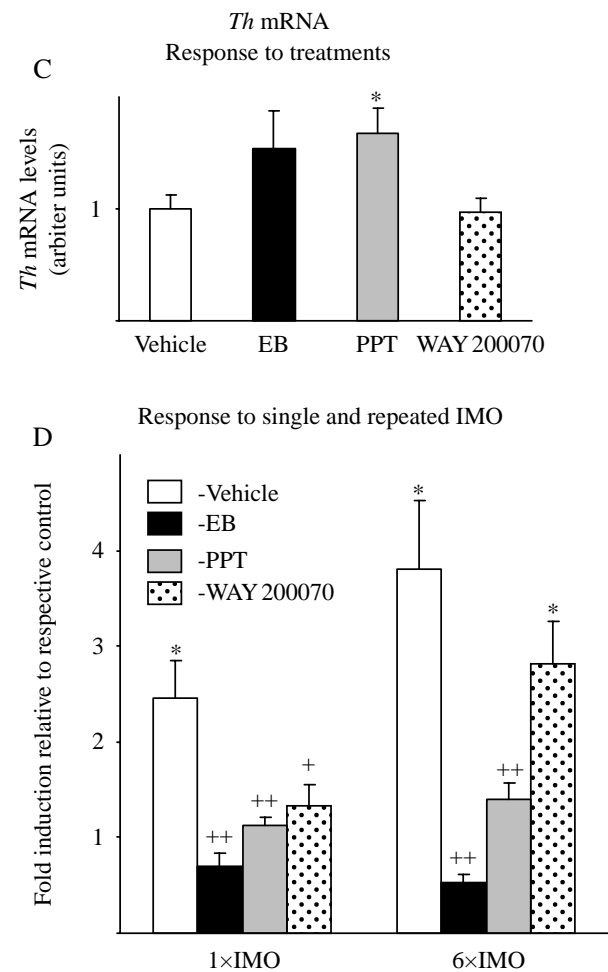

that control body fluid homeostasis (Hochstenbach \& Ciriello 1995, Lawrence \& Jarrott 1996). Noradrenergic neurons located throughout the rostral-medial NTS and most of the caudal (commissuralis) subnuclei of the NTS are barosensitive, and respond dynamically to alterations in blood pressure as part of the homeostatic cardiovascular control process. However, their functional role is not identical. The rostralmedial portion of the NTS exerts more control on the arterial system, while the caudal NTS is more selective for the cardiac system. Thus, it will be important to perform a more detailed response of subpopulations of CA neurons of the NTS to IMO stress.

$\mathrm{EB}$, as the findings indicate, can modulate the functional activity of noradrenergic neurons of the NTS during single IMO stress through $\mathrm{ER} \alpha$ as well as $\mathrm{ER} \beta$, since administration of $\mathrm{EB}$ and both selective agonists have similar ameliorative effects on Th in rostral-medial and caudal, and Dbh in caudal part of the NTS. A high density of ER $\alpha$ and ER $\beta$ has been demonstrated from caudal to medial regions of the NTS (Shughrue et al. 1997, Laflamme et al. 1998, Shughrue \& Merchenthaler 2001, Schlenker \& Hansen 2006). However, caudal NTS expression of $\mathrm{ER} \alpha$ is greater than that for $\mathrm{ER} \beta$ (Schlenker \& Hansen 2006). This might be a reason why pretreatment with EB as well as PPT was especially effective in preventing or attenuating changes in $T h$ and $D b h$ gene expression elicited by repeated IMO. In addition, the expression of ER subtypes might be selectively regulated by stress. Earlier studies revealed a significant elevation in ER immunoreactivity in the NTS of intact female rats after $1 \mathrm{~h}$ of IMO stress (Estacio et al. 1996).

The selectivity of the ER compounds were confirmed by changes in body and uterine weights. EB and PPT, but not WAY-200070, led to about 20\% reduction in body weight and increased the uterus weight, showing their association with the activation of ER $\alpha$. These data are in agreement with other studies concluding that prevention of body weight gain is associated with the activation of predominantly $\operatorname{ER} \alpha$ in adipose tissue (Heine et al. 2000, Wegorzewska et al. 2008). The effect of EB and the ER $\alpha$ agonist on body weight may be at least partially regulated by suppression of food intake in the NTS, since gastrointestinal signals generated by ingested food are first processed within the NTS (Sutton et al. 2004, Travagli et al. 2006, Valassi et al. 2008). Tracing studies revealed

Figure 3 Effect of long-term administration of EB or ER subtype-selective agonists on Th mRNA levels in rostral-medial and caudal parts of the NTS of OVX female rats following single or repeated immobilization stress. Changes in Th mRNA in rostralmedial (A and B) and caudal (C and D) parts of the NTS are shown. (A and C) Th mRNA levels expressed as mean \pm s.E.M. (6-8 samples per group) with levels of Th in vehicle-treated rats taken as 1 . ${ }^{*} P<0.05$ versus vehicle. (B and $\left.\mathrm{D}\right)$ Response to single $(1 \times)$ or repeated $(6 \times)$ IMO stress. Data are expressed as mean \pm s.E.M. with levels of Th mRNA with respective treatment in unstressed rats taken as $1 .{ }^{*} P<0 \cdot 05,{ }^{* * *} P<0 \cdot 001$ versus respective unstressed controls; ${ }^{+} P<0 \cdot 05,{ }^{+} P<0 \cdot 01$ vs $1 \times \mathrm{IMO} /$ vehicle or $6 \times 1 \mathrm{MO} /$ vehicle. 

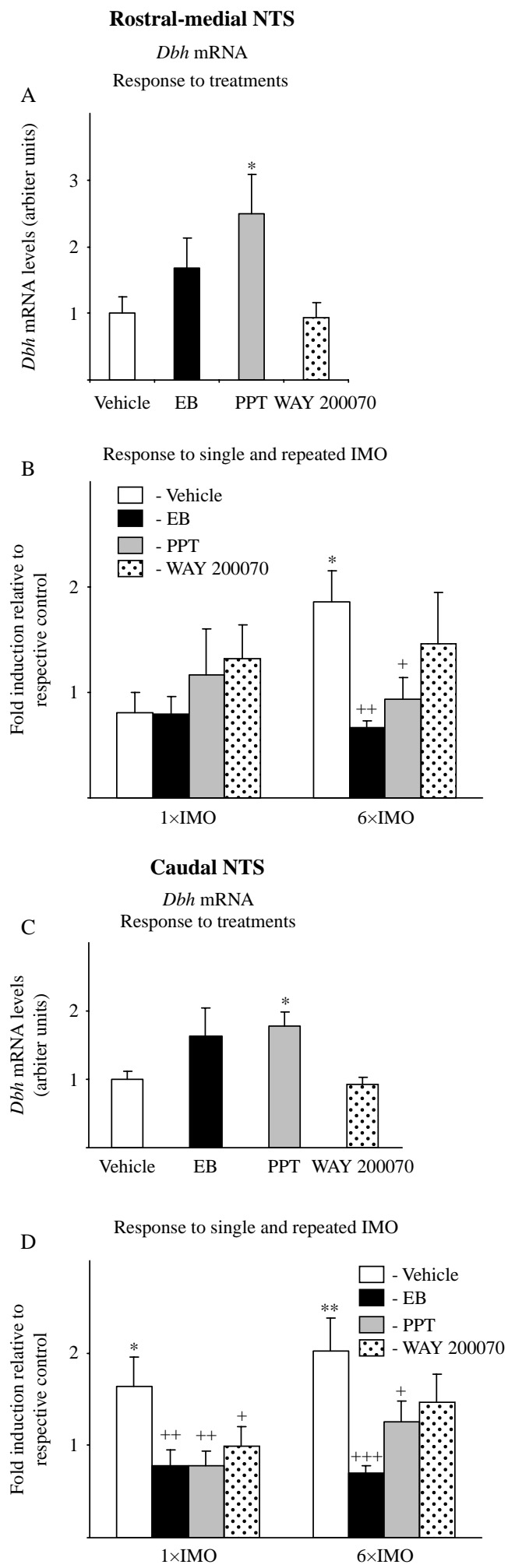

substantial axonal projections from the caudal NTS neurons to the immediately subjacent dorsal motor nucleus of the vagus, and that they are part of a gastro-gastric vago-vagal reflex (Rogers \& McCann 1993). Thus, estrogens via ER $\alpha$ may modulate brainstem circuits regulating gastric function.

It is interesting to note that in several areas, basal levels of $T h$ and $D b h$ were significantly elevated with PPT but not with EB treatment. It might be explained by the ying-yang relationship between ER $\alpha$ and ER $\beta$. Both ERs possess fairly similar binding affinities for $17 \beta$-estradiol, $0.2 \mathrm{nM}$ for $\mathrm{ER} \alpha$, and $0.6 \mathrm{nM}$ for $\mathrm{ER} \beta$ (Gustafsson \& Warner 2000). Compared with $\operatorname{ER} \alpha$, generally $\operatorname{ER} \beta$ has a weaker transcriptional activity, and it often functions oppositely or acts as a dominant negative regulator of estrogen signaling (Paech et al. 1997, Cowley \& Parker 1999). When coexpressed with ER $\alpha$, it causes a concentrationdependent reduction of ER $\alpha$-mediated transcriptional activation and the repression of ER $\alpha$-mediated effects (Hall \& McDonnell 1999).

Our results also clearly show that $\operatorname{ER} \alpha$, but not $\operatorname{ER} \beta$, is involved in estradiol-mediated elevation in corticosterone and attenuation of corticosterone response to IMO stress. Similar to our earlier studies, we demonstrated that EB could attenuate the elevation of corticosterone levels in response to single IMO (Serova et al. 2005). Here, we show for the first time that it can also modulate response to repeated IMO stress. In this regard, women receiving estradiol through extradermal patch $(0.1 \mathrm{mg})$ for 1 month had an attenuated elevation of cortisol to single endotoxin injection (Puder et al. 2001). The effects of EB on corticosterone levels with and without stress were similar in rats treated with PPT, indicating the involvement of ER $\alpha$. Recently, ER $\alpha$ was also found to mediate estrogen-mediated impairment of glucocorticoid negative feedback on the HPA axis (Weiser \& Handa 2009).

ER $\beta$ does not appear to mediate the corticosterone response shown in the present study as pretreatment with WAY-200070 for 21 days did not alter the rise in corticosterone with single 2-h IMO, or repeated 2-h IMO for six consecutive days. It also did not alter corticosterone levels in the absence of stress. In contrast, WAY-200070 given during 7 days is reported to reduce corticosterone levels $20 \mathrm{~min}$ after single forced swim test, indicating the importance of ER $\beta$ (Weiser et al. 2009). These differences

Figure 4 Effect of long-term administration of EB or ER subtype-selective agonists to OVX female rats on Dbh mRNA levels in rostral-medial and caudal parts of the NTS following single or repeated immobilization stress. Changes in Dbh mRNA in rostral-medial (A and B) and caudal parts (C and D) of the NTS are shown. (A and C) Dbh mRNA levels expressed as mean \pm s.E.M. (6-8 samples per group) with levels of $D b h$ in vehicle-treated rats taken as $1 .{ }^{*} P<0 \cdot 05$ versus vehicle. (B and D) Response to single $(1 \times)$ or repeated $(6 \times)$ IMO stress. Data are expressed as mean \pm s.E.M. with levels of $D b h$ mRNA with respective treatment in unstressed rats taken as $1 .{ }^{*} P<0 \cdot 05, * * P<0 \cdot 01$ versus respective unstressed controls; ${ }^{+} P<0.05,{ }^{++} P<0 \cdot 01,{ }^{++}+P<0 \cdot 001$ vs $1 \times \mathrm{IMO} /$ vehicle or $6 \times \mathrm{IMO} /$ vehicle. 
may be due to different duration and type of stress, as the neuronal pathways mediating the activation of the HPA axis depend on stress paradigms, stressor modality, and intensity (reviewed in Kvetnansky et al. (2009) and Ulrich-Lai \& Herman (2009)).

The changes in plasma corticosterone with EB and PPT could be due to a direct effect, or result from modulation of the HPA axis at the levels of ACTH or CRH. Transcriptional activity of $\mathrm{CRH}$ promoter was found to be stimulated more strongly with $\mathrm{ER} \beta$ than with $\mathrm{ER} \alpha$, and $\mathrm{ER} \beta$ is colocalized with CRH in rat PVN (Miller et al. 2004). However, recent data suggest that estrogens can also regulate $\mathrm{CRH}$ promoter activity through ER $\alpha$ (Lalmansingh \& Uht 2008). In addition, $\mathrm{ER} \alpha$ and $\mathrm{ER} \beta$ differentially regulate transcription of the human CRH-binding protein gene leading to downregulation of the HPA axis and reduction of corticosterone levels in stress conditions.

Are the estradiol or ER agonist-mediated changes observed in the noradrenergic neurons in the response to stress mediated by effects on the HPA axis? Since we used s.c. but not local administration, we cannot rule out the possibility that their effects on gene expression in the LC and NTS might be indirect. $\mathrm{CRH}$ neurons innervate the $\mathrm{LC}$, and can increase electrophysiological activity of noradrenergic neurons, noradrenaline synthesis, and release in prefrontal cortex and hypothalamus (Valentino \& Van Bockstaele 2001). Moreover, the LC and NTS express glucocorticoid receptors (Fuxe et al. 1987). Glucocorticoids can influence the expression of norepinephrine biosynthetic enzymes, at least in cell culture (Lewis et al. 1987, McMahon \& Sabban 1992, Hwang \& Joh 1993, Kim et al. 1993). It is possible that the attenuation of the induction of IMO-triggered elevations in the LC or NTS in EB- and PPT-treated rats is partially due to the inhibition of the corticosterone response to stress. This could also be due to alterations in the activation of NTS neurons in response to stress by input from PVN, since its lesions significantly suppressed the stress-related induction of c-Fos in NTS CA cells. Furthermore, tracer deposits in the NTS retrogradely labeled substantial numbers of PVN cells that were also Fos positive after stress (Dayas et al. 2004). However, the effectiveness of WAY-200070 in blocking the IMO-elicited rise in $\mathrm{TH}$ and $\mathrm{DBH}$ in the noradrenergic neurons, but not in plasma corticosterone, argues against solely a glucocorticoidmediated mechanism.

Conversely, the CA neurons from the LC as well as the NTS may contribute to the changes in the response of the HPA axis with stress observed in estradiol- or PPT-treated animals, since the hypothalamic PVN receives a major input from noradrenergic neurons in the NTS and innervation of lesser magnitude from the LC. Thus, noradrenaline can excite CRH-containing cells in the hypothalamic PVN to regulate the HPA axis (reviewed in Dunn \& Swiergiel (2008) and Ulrich-Lai \& Herman (2009)).

A number of important questions remain such as whether a higher concentration of WAY-200070 than used in this study might have a more potent effect on repeated IMO.
Future dose-response curves would be informative. It also remains to be determined whether chronic pretreatments are necessary to elicit the changes observed. It is still unclear whether the effects of estradiol and the ER agonists are direct or indirect and whether membrane or nuclear ERs are involved. In this regard, TH promoter activity was recently found to respond to estradiol by a membrane $\mathrm{ER} \alpha$ mediated pathway (Maharjan et al. 2010).

In sum, the findings of this study demonstrate that estradiol and ER-selective agonists can markedly attenuate the response of norepinephrine biosynthetic enzymes in the LC and NTS and activation of the HPA axis, with ER selectivity depending on the duration of the stress. These findings demonstrate the mechanisms that likely contribute to differences in susceptibility to stress-related disorders depending on hormonal status.

\section{Declaration of interest}

The authors declare that there is no conflict of interest that could be perceived as prejudicing the impartiality of the research reported.

\section{Funding}

This work was partially supported by grant NS 28869 from the National Institutes of Health (ES) and by Wyeth Research.

\section{References}

Arbogast LA \& Hyde JF 2000 Estradiol attenuates the forskolin-induced increase in hypothalamic tyrosine hydroxylase activity. Neuroendocrinology 71 219-227.

Baum A \& Grunberg NE 1991 Gender, stress, and health. Health Psychology $1080-85$.

Burgess LH \& Handa RJ 1992 Chronic estrogen-induced alterations in adrenocorticotropin and corticosterone secretion, and glucocorticoid receptor-mediated functions in female rats. Endocrinology 131 1261-1269.

Cowley SM \& Parker MG 1999 A comparison of transcriptional activation by ER $\alpha$ and ER $\beta$. Journal of Steroid Biochemistry and Molecular Biology 69 165-175.

Critchlow V, Liebelt RA, Bar-Sela M, Mountcastle W \& Lipscomb HS 1963 Sex difference in resting pituitary-adrenal function in the rat. American Journal of Physiology 205 807-815.

Dayas CV, Xu Y, Buller KM \& Day TA 2000 Effects of chronic oestrogen replacement on stress-induced activation of hypothalamic-pituitaryadrenal axis control pathways. Journal of Neuroendocrinology 12 784-794.

Dayas CV, Buller KM \& Day TA 2004 Hypothalamic paraventricular nucleus neurons regulate medullary catecholamine cell responses to restraint stress. Journal of Comparative Neurology 478 22-34.

Dunn AJ \& Swiergiel AH 2008 The role of corticotropin-releasing factor and noradrenaline in stress-related responses, and the inter-relationships between the two systems. European Journal of Pharmacology 583 186-193.

Enmark E \& Gustafsson JA 1999 Oestrogen receptors - an overview. Journal of Internal Medicine 246 133-138.

Estacio MA, Yamada S, Tsukamura H, Hirunagi K \& Maeda K 1996 Effect of fasting and immobilization stress on estrogen receptor immunoreactivity in the brain in ovariectomized female rats. Brain Research 717 55-61.

Figueiredo HF, Dolgas CM \& Herman JP 2002 Stress activation of cortex and hippocampus is modulated by sex and stage of estrus. Endocrinology 143 2534-2540. 
Fuxe K, Cintra A, Agnati LF, Harfstrand A, Wikstrom AC, Okret S, Zoli M, Miller LS, Greene JL \& Gustafsson JA 1987 Studies on the cellular localization and distribution of glucocorticoid receptor and estrogen receptor immunoreactivity in the central nervous system of the rat and their relationship to the monoaminergic and peptidergic neurons of the brain. Journal of Steroid Biochemistry 27 159-170.

Gustafsson JA \& Warner M 2000 Estrogen receptor $\beta$ in the breast: role in estrogen responsiveness and development of breast cancer. Journal of Steroid Biochemistry and Molecular Biology 74 245-248.

Hall JM \& McDonnell DP 1999 The estrogen receptor $\beta$-isoform (ER $\beta$ ) of the human estrogen receptor modulates $\mathrm{ER} \alpha$ transcriptional activity and is a key regulator of the cellular response to estrogens and antiestrogens. Endocrinology 140 5566-5578.

Harris HA 2007 Estrogen receptor-beta: recent lessons from in vivo studies. Molecular Endocrinology 21 1-13.

Harris HA, Katzenellenbogen JA \& Katzenellenbogen BS 2002 Characterization of the biological roles of the estrogen receptors, ERalpha and ERbeta, in estrogen target tissues in vivo through the use of an ERalphaselective ligand. Endocrinology 143 4172-4177.

Heine PA, Taylor JA, Iwamoto GA, Lubahn DB \& Cooke PS 2000 Increased adipose tissue in male and female estrogen receptor-alpha knockout mice. PNAS 97 12729-12734.

Helgason S, Carlstrom K, Damber MG, Damber JE, Selstam G \& von Schoultz B 1981 Effects of various oestrogens on circulating androgens and cortisol during replacement therapy in post-menopausal women. Maturitas 3 301-308.

Hochstenbach SL \& Ciriello J 1995 Plasma hypernatremia induces c-fos activity in medullary catecholaminergic neurons. Brain Research 674 46-54.

Hwang O \& Joh TH 1993 Effects of cAMP, glucocorticoids, and calcium on dopamine beta-hydroxylase gene expression in bovine chromaffin cells. Journal of Molecular Neuroscience 4 173-183.

Kajantie E \& Phillips DI 2006 The effects of sex and hormonal status on the physiological response to acute psychosocial stress. Psychoneuroendocrinology 31 151-178.

Kim KT, Park DH \& Joh TH 1993 Parallel up-regulation of catecholamine biosynthetic enzymes by dexamethasone in PC12 cells. Journal of Neurochemistry 60 946-951.

Klinge CM 2001 Estrogen receptor interaction with estrogen response elements. Nucleic Acids Research 29 2905-2919.

Krezel W, Dupont S, Krust A, Chambon P \& Chapman PF 2001 Increased anxiety and synaptic plasticity in estrogen receptor beta -deficient mice. PNAS 98 12278-12282.

Kvetnansky R, Sabban EL \& Palkovits M 2009 Catecholaminergic systems in stress: structural and molecular genetic approaches. Physiological Reviews $\mathbf{8 9}$ 535-606.

Laflamme N, Nappi RE, Drolet G, Labrie C \& Rivest S 1998 Expression and neuropeptidergic characterization of estrogen receptors (ERalpha and ERbeta) throughout the rat brain: anatomical evidence of distinct roles of each subtype. Journal of Neurobiology 36 357-378.

Lalmansingh AS \& Uht RM 2008 Estradiol regulates corticotropin-releasing hormone gene (crh) expression in a rapid and phasic manner that parallels estrogen receptor-alpha and -beta recruitment to a $3^{\prime}, 5^{\prime}$-cyclic adenosine $5^{\prime}$-monophosphate regulatory region of the proximal crh promoter. Endocrinology 149 346-357.

Lawrence AJ \& Jarrott B 1996 Neurochemical modulation of cardiovascular control in the nucleus tractus solitarius. Progress in Neurobiology 48 21-53.

Lewis EJ, Harrington CA \& Chikaraishi DM 1987 Transcriptional regulation of the tyrosine hydroxylase gene by glucocorticoid and cyclic AMP. PNAS 84 3550-3554.

Liaw JJ, He JR, Hartman RD \& Barraclough CA 1992 Changes in tyrosine hydroxylase mRNA levels in medullary A1 and A2 neurons and locus coeruleus following castration and estrogen replacement in rats. Brain Research. Molecular Brain Research 13 231-238.

Lund TD, Rovis T, Chung WC \& Handa RJ 2005 Novel actions of estrogen receptor-beta on anxiety-related behaviors. Endocrinology 146 797-807.

Luque JM, de Blas MR, Segovia S \& Guillamon A 1992 Sexual dimorphism of the dopamine-beta-hydroxylase-immunoreactive neurons in the rat locus ceruleus. Brain Research. Developmental Brain Research 67 211-215.
Maharjan S, Serova L \& Sabban EL 2005 Transcriptional regulation of tyrosine hydroxylase by estrogen: opposite effects with estrogen receptors alpha and beta and interactions with cyclic AMP. Journal of Neurochemistry 93 1502-1514.

Maharjan S, Serova LI \& Sabban EL 2010 Membrane-initiated estradiol signaling increases tyrosine hydroxylase activity with $\mathrm{ER} \alpha$ in PC12 cells. Journal of Neurochemistry 112 42-55.

Malamas MS, Manas ES, McDevitt RE, Gunawan I, Xu ZB, Collini MD, Miller CP, Dinh T, Henderson RA, Keith JC Jr et al. 2004 Design and synthesis of aryl diphenolic azoles as potent and selective estrogen receptor-beta-ligands. Journal of Medicinal Chemistry 47 5021-5040.

Matthews J \& Gustafsson JA 2003 Estrogen signaling: a subtle balance between ER alpha and ER beta. Molecular Interventions 3 281-292.

McKenna NJ, Lanz RB \& O'Malley BW 1999a Nuclear receptor coregulators: cellular and molecular biology. Endocrine Reviews 20 321-344.

McKenna NJ, Xu J, Nawaz Z, Tsai SY, Tsai MJ \& O’Malley BW 19996 Nuclear receptor coactivators: multiple enzymes, multiple complexes, multiple functions. Journal of Steroid Biochemistry and Molecular Biology 69 3-12.

McMahon A \& Sabban EL 1992 Regulation of expression of dopamine beta-hydroxylase in PC12 cells by glucocorticoids and cyclic AMP analogues. Journal of Neurochemistry 59 2040-2047.

Melia KR, Rasmussen K, Terwilliger RZ, Haycock JW, Nestler EJ \& Duman RS 1992 Coordinate regulation of the cyclic AMP system with firing rate and expression of tyrosine hydroxylase in the rat locus coeruleus: effects of chronic stress and drug treatments. Journal of Neurochemistry $\mathbf{5 8}$ 494-502.

Miller WJ, Suzuki S, Miller LK, Handa R \& Uht RM 2004 Estrogen receptor (ER)beta isoforms rather than ERalpha regulate corticotropin-releasing hormone promoter activity through an alternate pathway. Journal of Neuroscience 24 10628-10635.

Miller NR, Jover T, Cohen HW, Zukin RS \& Etgen AM 2005 Estrogen can act via estrogen receptor alpha and beta to protect hippocampal neurons against global ischemia-induced cell death. Endocrinology 146 3070-3079.

Mitra SW, Hoskin E, Yudkovitz J, Pear L, Wilkinson HA, Hayashi S, Pfaff DW, Ogawa S, Rohrer SP, Schaeffer JM et al. 2003 Immunolocalization of estrogen receptor beta in the mouse brain: comparison with estrogen receptor alpha. Endocrinology 144 2055-2067.

Osterhout CA, Sterling CR, Chikaraishi DM \& Tank AW 2005 Induction of tyrosine hydroxylase in the locus coeruleus of transgenic mice in response to stress or nicotine treatment: lack of activation of tyrosine hydroxylase promoter activity. Journal of Neurochemistry 94 731-741.

Ostlund H, Keller E \& Hurd YL 2003 Estrogen receptor gene expression in relation to neuropsychiatric disorders. Annals of the New York Academy of Sciences 1007 54-63.

Paech K, Webb P, Kuiper GG, Nelsson S, Gustafsson J, Kushner PJ \& Scanlan TS 1997 Differential ligand activation of estrogen receptors $\mathrm{ER} \alpha$ and ER $\beta$ at AP1 sites. Science 277 1508-1510.

Patchev VK, Hayashi S, Orikasa C \& Almeida OF 1995 Implications of estrogen-dependent brain organization for gender differences in hypothalamo-pituitary-adrenal regulation. FASEB Journal 9 419-423.

Patrone C, Pollio G, Vegeto E, Enmark E, de Curtis I, Gustafsson JA \& Maggi A 2000 Estradiol induces differential neuronal phenotypes by activating estrogen receptor alpha or beta. Endocrinology 141 1839-1845.

Pau KY, Hess DL, Kohama S, Bao J, Pau CY \& Spies HG 2000 Oestrogen upregulates noradrenaline release in the mediobasal hypothalamus and tyrosine hydroxylase gene expression in the brainstem of ovariectomized rhesus macaques. Journal of Neuroendocrinology 12 899-909.

Pendergast JS, Tuesta LM \& Bethea JR 2008 Oestrogen receptor beta contributes to the transient sex difference in tyrosine hydroxylase expression in the mouse locus coeruleus. Journal of Neuroendocrinology 20 1155-1164.

Pfaff D, Frohlich J \& Morgan M 2002 Hormonal and genetic influences on arousal-sexual and otherwise. Trends in Neuroscience 25 45-50.

Puder JJ, Freda PU, Goland RS \& Wardlaw SL 2001 Estrogen modulates the hypothalamic-pituitary-adrenal and inflammatory cytokine responses to endotoxin in women. Journal of Clinical Endocrinology and Metabolism 86 2403-2408. 
Rogers RC \& McCann MJ 1993 Intramedullary connections of the gastric region in the solitary nucleus: a biocytin histochemical tracing study in the rat. Journal of the Autonomic Nervous System 42 119-130.

Rusnak M, Zorad S, Buckendahl P, Sabban EL \& Kvetnansky R 1998 Tyrosine hydroxylase mRNA levels in locus ceruleus of rats during adaptation to long-term immobilization stress exposure. Molecular and Chemical Neuropathology 33 249-258.

Sabban EL 2007 Catecholamines in stress: molecular mechanisms of gene expression. Endocrine Regulations 41 61-73.

Sabban EL \& Kvetnansky R 2001 Stress-triggered activation of gene expression in catecholaminergic systems: dynamics of transcriptional events. Trends in Neuroscience 24 91-98.

Sabban E, Maharjan S, Nastromo G \& Serova L 2010 Divergent effects of estradiol on gene expression of catecholamine biosynthetic enzymes. Physiology \& Behavior 99 163-168.

Scharfman HE \& MacLusky NJ 2008 Estrogen-growth factor interactions and their contributions to neurological disorders. Headache 48 (Suppl 2) S77-S89.

Schlenker EH \& Hansen SN 2006 Sex-specific densities of estrogen receptors alpha and beta in the subnuclei of the nucleus tractus solitarius, hypoglossal nucleus and dorsal vagal motor nucleus weanling rats. Brain Research 1123 89-100.

Serova LI, Nankova BB, Feng Z, Hong JS, Hutt M \& Sabban EL 1999 Heightened transcription for enzymes involved in norepinephrine biosynthesis in the rat locus coeruleus by immobilization stress. Biological Psychiatry 45 853-862.

Serova L, Rivkin M, Nakashima A \& Sabban EL 2002 Estradiol stimulates gene expression of norepinephrine biosynthetic enzymes in rat locus coeruleus. Neuroendocrinology 75 193-200.

Serova LI, Maharjan S, Huang A, Sun D, Kaley G \& Sabban EL 2004 Response of tyrosine hydroxylase and GTP cyclohydrolase I gene expression to estrogen in brain catecholaminergic regions varies with mode of administration. Brain Research 1015 1-8.

Serova LI, Maharjan S \& Sabban EL 2005 Estrogen modifies stress-response of catecholamine biosynthetic enzyme genes and cardiovascular system in ovariectomized female rats. Neuroscience 132 249-259.

Shughrue PJ \& Merchenthaler I 2001 Distribution of estrogen receptor beta immunoreactivity in the rat central nervous system. Journal of Comparative Neurology 436 64-81.

Shughrue PJ, Lane MV \& Merchenthaler I 1997 Comparative distribution of estrogen receptor-alpha and -beta mRNA in the rat central nervous system. Journal of Comparative Neurology 388 507-525.

Smith MA, Brady LS, Glowa J, Gold PW \& Herkenham M 1991 Effects of stress and adrenalectomy on tyrosine hydroxylase mRNA levels in the locus ceruleus by in situ hybridization. Brain Research 544 26-32.

Stauffer SR, Coletta CJ, Tedesco R, Nishiguchi G, Carlson K, Sun J, Katzenellenbogen BS \& Katzenellenbogen JA 2000 New pyrazole ligands: Structure-affinity/activity relationships and estrogen receptor- $\alpha-$ selective agonists. Journal of Medicinal Chemistry 43 4934-4947.

Stovall DW \& Pinkentorn JAV 2008 Estrogen agonist/antagonists in combination with estrogen for prevention and treatment of menopauseassociated signs and symptoms. Women's Health 4 257-268.

Sutton GM, Patterson LM \& Berthoud HR 2004 Extracellular signalregulated kinase $1 / 2$ signaling pathway in solitary nucleus mediates cholecystokinin-induced suppression of food intake in rats. Journal of Neuroscience 24 10240-10247.
Ter Horst GJ, Wichmann R, Gerrits M, Westenbroek C \& Lin Y 2009 Sex differences in stress-responses: focus on ovarian hormones. Physiology and Behavior 97 239-249.

Travagli RA, Hermann GE, Browning KN \& Rogers RC 2006 Brainstem circuits regulating gastric function. Annual Review of Physiology 68 279-305.

Ueyama T, Ishikura F, Matsuda A, Asanuma T, Ueda K, Ichinose M, Kasamatsu K, Hano T, Akasaka T, Tsuruo Y et al. 2007 Chronic estrogen supplementation following ovariectomy improves the emotional stressinduced cardiovascular responses by indirect action on the nervous system and by direct action on the heart. Circulation Journal $71565-573$.

Ulrich-Lai YM \& Herman JP 2009 Neural regulation of endocrine and autonomic stress-responses. Nature Reviews. Neuroscience 10 397-409.

Valassi E, Scacchi M \& Cavagnini F 2008 Neuroendocrine control of food intake. Nutrition, Metabolism, and Cardiovascular Diseases 18 158-168.

Valentino RJ \& Van Bockstaele E 2001 Opposing regulation of the locus coeruleus by corticotropin-releasing factor and opioids. Potential for reciprocal interactions between stress and opioid sensitivity. Psychopharmacology 158 331-342.

Walf AA \& Frye CA 2005 Antianxiety and antidepressive behavior produced by physiological estradiol regimen may be modulated by hypothalamicpituitary-adrenal axis activity. Neuropsychopharmacology 30 1288-1301.

Walf AA \& Frye CA 2008 Rapid and estrogen receptor beta mediated actions in the hippocampus mediate some functional effects of estrogen. Steroids $\mathbf{7 3}$ 997-1007.

Walf AA, Koonce CJ \& Frye CA 2009 Adult female wildtype, but not oestrogen receptor \{beta\} knockout, mice have decreased depression-like behaviour during pro-oestrus and following administration of oestradiol or diarylpropionitrile. Journal of Psychopharmacology 23 442-450.

Wang P, Kitayama I \& Nomura J 1998 Tyrosine hydroxylase gene expression in the locus coeruleus of depression-model rats and rats exposed to short-and long-term forced walking stress. Life Sciences 62 2083-2092.

Wegorzewska IN, Walters K, Weiser MJ, Cruthirds DF, Ewell E, Larco DO, Handa RJ \& Wu TJ 2008 Postovariectomy weight gain in female rats is reversed by estrogen receptor alpha agonist, propylpyrazoletriol. American Journal of Obstetrics and Gynecology 67 e61-e65.

Weiser MJ \& Handa RJ 2009 Estrogen impairs glucocorticoid dependent negative feedback on the hypothalamic-pituitary-adrenal axis via estrogen receptor alpha within the hypothalamus. Neuroscience 159 883-895.

Weiser MJ, Wu TJ \& Handa RJ 2009 Estrogen receptor $\beta$ (ER $\beta)$ agonist diarylpropionitrile (DPN): biological activities of R- and S-enantiomers on behavior and hormonal response to stress. Endocrinology 150 1817-1825.

Young EA, Altemus M, Parkison V \& Shastry S 2001 Effects of estrogen antagonists and agonists on the ACTH response to restraint stress in female rats. Neuropsychopharmacology 25 881-891.

\section{Received in final form 10 March 2010 \\ Accepted 26 March 2010 \\ Made available online as an Accepted Preprint 26 March 2010}

